\title{
Environmental Attitude as a Mediator of the Relationship between Self-concept, Environmental Self-Efficacy and Responsible Environmental Behaviour among Residents of High Density Areas in Ibadan Metropolis, Nigeria 1Ojedokun, A. Oluyinka and ${ }^{2}$ Balogun, S.K
}

\begin{abstract}
This study investigated environmental attitude as a mediator in the relationship between self-concept, environmental-self-efficacy and responsible environmental behaviour among residents of high-density areas in Ibadan metropolis. The sample consists of one thousand, three hundred and sixty participants that comprised five hundred and seventy six from Ibadan South East and seven hundred and eighty-four from Ibadan North East Local Government areas selected using a multi-stage sampling technique (purposive, proportional, and simple random). Data collection was through a self-reported questionnaire that measured demographic factors, selfconcept, environmental-self-efficacy, environmental attitude and responsible environmental behaviour. Multiple regression statistical analysis is the technique of data analysis. Results indicate that self-concept, environmental self-efficacy, and environmental attitude jointly contribute $18 \%$ to variance in responsible environmental behaviour. Independently, self-concept $(\beta$ ? $=-0.16 ., t=-4.82 ., p<.01)$ and environmental-selfefficacy $(\beta$ ] [ ] = - 0.11., $t=3.08 ., p<.01$ ) respectively contributed significantly to responsible environmental behaviour. Lastly, environmental attitude $(\beta$ ] [] $=-0.23 ., t=-8.53 ., p<.01)$ significantly mediates the relationship between self-concept, environmental self-efficacy, and responsible environmental behaviour. Discussion focuses on the relevance of environmental attitude in the person-environment transactions. It was recommended that psychologists should design personally relevant environmental attitude change strategies to improve responsible environmental behaviour.
\end{abstract}

Keywords: Responsible environmental behaviour, Self concept, Environmental self efficacy, Attitude, High density areas, Ibadan metropolis

\section{Introduction}

One of the challenges facing Oyo State government in Nigeria is how to reduce urban litters in Ibadan metropolis. Indeed, attempts to sensitize, and alert residents to be more responsible in their environmental behaviour seem to have become part of the projects of Oyo State government. These attempts include promulgation of Oyo State environmental law by the State House of Assembly in 2008, establishment of the Ministry of Environment and Water Resources in 2001, the kerbsides street sweeping innovation in 1999, and the edict establishing the Ibadan Waste Management Authority (Gazette No 8, Vol. 22 of $16^{\text {th }}$ May 1997). All as part of the attempts to make Ibadan city wear a good look. Yet, Ibadan is dirty going by daily media reports and personal observations of the researchers. This subject matter is becoming a behavioural problem, and indeed requires a psychological intervention. Consequences of less engagement in responsible environmental behaviour include financial and manpower costs associated with cleaning activities, health hazards, bad odour, proliferation of flies, cockroaches, rats, and other small and dangerous insects which breed ailments that may endanger human health.
To achieve success in the agenda of the Oyo State government to keep Ibadan metropolis clean, an understanding of the factors that can motivate, or inhibit individuals to engage in responsible environmental behaviour is important. To further the goal of factors predicting human environmental behaviour, and any possible mediator, this present study investigates environmental attitude as a mediator in the relationship between selfconcept, environmental self-efficacy, and responsible environmental behaviour among residents of high density areas in Ibadan metropolis, Nigeria, This effort might assist policy formulators and researchers alike in developing effective communication strategies that can make responsible environmental behaviour more desirable.

The term responsible environmental behaviour (REB) has many meanings. Iwata (2001) describes REB as categories of behaviour such as recycling and energy conservation, which can help to alleviate the alarmingly rapid deterioration of the global environment. To Sivek and Hungerford (1989-1990), it is any individual or group action that aim at doing what is right to help protect the environment in general daily practice (environmental activism), for example recycling and energy 
conservation. Hansman and Scholz (2003) refer to it as reduction in littering, or reduction in careless, and incorrect disposal of waste. Ojedokun (2009) conceptualizes it as littering (individual's intentional or unintentional placement of domestic wastes in the public and private domains). Considerable research exists concerning the descriptions and predictors of individuals' responsible environmental behaviour. For example, Corbett (2005), Adams (2003), Hwang, Kim, and Jeng (2000), and Hines, Hungerford, and Tomera (1987) have implicated personality factors on both environmental attitude and responsible environmental behaviour. Specifically, responsible environmental behaviour model of Hines et al (1987), which is an improvement on the Ajzen's theory of planned behaviour (1987), suggests that some personality factors such as locus of control (ability/opportunity to affect change), and self-efficacy (feelings of competency and effectiveness in participating in pro- environmental behaviours) promote responsible environmental behaviour. The shortcoming of this model according to Hines et al (1987) is that unlike cognitive variables, the personality factors identified are not readily amenable to training efforts in influencing responsible environmental behaviour.

In searching for a cognitive variable that is amenable to training, the researchers' attentions are drawn to the construct of environmental attitude. This choice is due to the importance of attitude in biasing perceptions and directing social behaviour (Eagly \& Chaiken, 1993). Information about people's attitude has been proved to enhance the relationship between personal characteristics and behaviour; and also assist in behaviour change across a multitude of situations (Hines et al. 1987; Monroe, Day, \& Greiser, 2000; McKenzie-Mohr \& Smith, 1999). If consistent relationships are found between two variables as highlighted above, then, it is possible to intervene on one in the hope that the intervention enhances the other. Unfortunately, the assumed linear relationship between personality factors and responsible environmental behaviour described by Hines et al. (1987) fails to consider the mediatory role of environmental attitude on this relationship. Considering this observation, it is then propose that environmental attitude will mediate the relationship between environmental self- efficacy, self-concept, and responsible environmental behaviour.

According to Holahan (1982) environmental attitude is people's favourable or unfavourable feeling toward some features of the physical environment, or toward an issue which pertains to the physical environment. Schultz, Shriver, Tabanico, and Khazian (2004) define environmental attitude as the collection of beliefs, affect, and behavioural intentions a person holds regarding an environmentally related activities, or issues.

Though Johnson, Bowker and Cordell (2004) report that environmental attitude positively predict environmental behaviour. However, to the best knowledge of the researchers, there is paucity of researches on the relationship between environmental attitude and responsible environmental behaviour in Nigeria. The only effort made to influence environmental behaviour through environmental attitude (that is, participation in monthly sanitation activities by every member of the public) was in 1983 during Buhari/Idiagbon administration. Aside from this effort, review of literature reveals no published research that has described the mediatory role of environmental attitude on the relationship between personality factors and responsible environmental behaviour. Therefore, this study is designed to fill such research gaps in Nigeria.

Personality factors play many roles in shaping human attitude and behaviour in various settings (Mischel, 1986). This observation suggests personality traits can inhibit, or enhance environmental attitude, and responsible environmental behaviour. For example, individuals may engage in responsible environmental behaviour to reflect their unique personality traits. Therefore, individuals are more likely to engage in behaviour that is consistent with their personality make up. Personality factors considered in this study are self-concept and environmental self-efficacy.

Hamachek (1981) defines self-concept (SC) as the set of perceptions or reference points that individual has about him/her self. Hamachek further states that self concept is the set of characteristics, attributes, qualities and deficiencies, capacities, limits, values, and relationships that individual knows to be descriptive of himself (or herself), and which 
he (or she) perceives as data concerning his (or her) identity. However, a common definition of self-concept is the one based on the theoretical model and definition proposed by Shavelson, Hubner, and Stanton (1976), it is the perception that individual has about self, formed from experiences, relationship with the environment, and significant others. Considering this finding, self-concept is expected to relate significantly to environmental attitude and responsible environmental behaviour.

Self-efficacy is the beliefs about capabilities to exercise control over events that affect lives (Arnould, Price, \& Zinkhan, 2004). It also refers to the perception by an individual that he or she has the knowledge and skills needed to conform to his or her attitudes and beliefs (Axlerod \& Lehman, 1993). In consonant with the definition of self-efficacy, environmental self-efficacy therefore refers to the feelings of competency, and effectiveness in carrying out a desire behaviour relating to the environment. People may not act unless they have reasonable reasons in their potential capacity. This self-belief factor may influence observation of responsible environmental behaviour and environmental attitude, in that those individuals who believe they have requisite skills are more likely to manifest more responsible environmental behaviour. Research has demonstrated self-efficacy influences choice of actions and the amount of energy invested in a task and the length of time during which individuals persevere without achieving the desired results (Busch, Fallan, \& Petterson, 1996). Considering this finding it is expected that environmental self-efficacy will be related to environmental attitude and responsible environmental behaviour.

\section{Hypotheses}

Based on the literature reviewed, the following hypotheses are tested:

1. There is a significant positive relationship between self-concept, environmental selfefficacy, and environmental attitude.

2. There is a significant negative relationship between self-concept, environmental selfefficacy, and responsible environmental behaviour.

3. Environmental attitude will significantly mediate the relationship between self-concept, environmental self-efficacy, and responsible environmental behaviour.

\section{Study Area.}

Ibadan is an urban city located in the humid Southwest of Nigeria, and is the capital city of Oyo State. It is on a major transport route to the northern parts of Nigeria, and is the largest of contemporary traditional Yoruba towns. Ibadan is composed of the main city, and its suburbs. Administratively, Ibadan metropolis was under one local government, the Ibadan Municipal Government, before it was splited into five distinct local government areas (LGA) in 1991. The five LGAs are Northeast, North Central, Northwest Southeast, and Southwest. Urban cores (high-density) and hinterlands (low-density) characterized Ibadan metropolis. Out of the five local government areas in Ibadan metropolis, data collection was among residents in Ibadan Northeast and Southeast local government areas.

Justifications for their selection include, the residents of these two local government areas share similar socioeconomic background with residents in the remaining three local governments, the two local government areas comprise of both urban cores (high density), and hinterlands (low density) areas. This composition characterizes the remaining three local government areas. However, Ibadan Northeast and Southeast local government areas contain the largest urban cores (high density) and few or pocket of hinterlands (low-density) areas in the metropolis. The choice of these two local government areas ensures that the environment is identical for all the participants.

\section{Methodology}

Sample and Sampling Procedure.

This utilizes a co-relational research design where no variable of interest is manipulated but are allowed to vary with each other. Survey method of data collection was adopted where questionnaires are used to collect data from the respondents on the studied variables. Analyses included descriptive statistics, correlation to examine the relationship among variables of the study, and multilevel simple linear multiple regression analysis to test for the mediatory role of environmental attitude on the relationship between self-concept, environmental self-efficacy, and responsible environmental behaviour. Step 1 of the multilevel simple linear multiple regression analysis involves regressing environmental attitude on self-concept and environmental self-efficacy, step 2 involves regressing 
responsible environmental behaviour on selfconcept and environmental self-efficacy, and step 3 involves entering self-concept, environmental self-efficacy, and environmental attitude simultaneously on responsible environmental behaviour.

One thousand, three hundred and sixty $(n=1360)$ participants selected through multistage sampling technique participated in the study. Firstly, urban cores (high density) and hinterlands (low-density) areas in Ibadan Northeast and Southeast local government areas were identified according to the recommendation of Mabogunje (1963). Secondly, through the lists of localities in the final results of 1991 population census of Nigeria, thirty two $(n=32)$ communities located within Ibadan North East Local Government Area and another twenty nine $(n=29)$ communities located within Ibadan South East Local Government Area were identified. Thirdly, after the identification of these communities, the researchers used simple random technique, specifically, odd and even technique to select at least fifty percent (50\%) of the communities from each local government area. These communities were selected from both urban cores (high density) and hinterland (low-density) using proportional sampling method.

Fourthly, after calculating the number of questionnaires to be administered in each community, a total of 2,000 questionnaires comprising of the demographic information, self-concept, environmental self-efficacy, environmental attitude, and responsible environmental behaviour were administered to the randomly selected residents of the two local government areas involved in this study by the researchers. The consent of the respondents was obtained, and the purpose of the study was explained to them before distributing the instrument.

After questionnaires administration and retrieval which lasted for a period of 4 months, a total of 1,520 questionnaires were collected back, out of these, 1360 questionnaires were found usable for data analysis. The rest were rejected due to missing information. Out of 1360 questionnaires returned, five hundred and seventy six (576, 42.4\%) participants were from fifteen communities in Ibadan South East Local Government Area, while 784 (57.6\%) participants were from sixteen communities in
Ibadan North East Local Government Area. Their ages ranged from 18 to 65 years (Mean= 32.36, $\mathrm{Sd}=10.98)$. They study comprised of males $(770,56.6 \%)$ and females $(590,43.4 \%)$. Their marital status varied from single (668, $49.1 \%)$, married $(599,44.0 \%)$, divorced (32, $2.4 \%)$, separated $(31,2.3 \%)$, and widowed (30, 2.2\%). Their educational qualifications also varied; primary leaving school certificates (225, 16.5\%), secondary school education $(523,38.5 \%)$, teacher training certificates $(222$, $16.4 \%)$, OND/NCE certificates $(268,19.7 \%)$, HND/First Degree education $(88,6.5 \%)$, and postgraduate qualifications $(34,2.5 \%)$.

\section{Description of Variables.}

The biographical data information sheet was used to collect information on the participants' gender (male or female), marital status (married, single, divorced, separated, or widowed), age in years, and highest educational qualification.

Environmental Self-Efficacy Scale (ESES) is a 5-item scale developed by Harkness, Scholz and Stadler (2002). The scale is the English version of the 5-item German version of this scale developed by Harkness et al. (2002). The response pattern is on 5-point Likert format of "Strongly Agree $=5$ to Strongly Disagree $=1$ ". Harkness et al. (2002) reported reliability coefficient of .86 for the scale. The items on the scale were subjected to item total correlation analysis in this study and using the Lawshe (1975) minimum content validity ratio (CVR) of .40;<.05 significance level. An overall alpha co-efficient of .84 and Unequal length Spearman-Brown split half reliability of .81 for the scale in this study.

Self-concept Scale (SC) is a 13-item bipolar adjective pairs developed by Devins, Beanlands, Mandin, and Paul (1997). The scale represents three dimensions of meaning according to Osgood, Suci, and Tannenbaum (1957): evaluation, potency, and activity. It uses a 7-point format to rate each of the selfconcept item- "my self as I am now". For easy understanding and comprehension by participants; and to be consistent with response pattern of other scales, the response was changed to 5-point Likert format of "Strongly Agree $=5$ to Strongly Disagree $=1$ ". The items on the scale were subjected to item total correlation analysis in this study and using the Lawshe (1975) minimum content validity ratio (CVR) of .40; <.05 significance level. The researcher obtained an overall alpha co- 
efficient of .80 and Equal length SpearmanBrown split half reliability of .81 for the scale in this study.

Environmental Attitude Scale (EAS) is a 24item scale developed by Ojedokun (2009) based on the three components of attitude cognition, affection and connative, or behavioural. It is a self-report questionnaire with response pattern in Likert format ranging from "Strongly Agree=5" to "Strongly Disagree $=1 "$, so that high score above the mean value represents positive environmental attitude and low score below the mean value indicates negative environmental attitude. The scale demonstrated good internal consistency in this study with an alpha coefficient of .86 and Spearman-Brown split half reliability of .92.

Responsible Environmental Behaviour Scale (REBS) is a 44-item scale developed by Ojedokun (2009). The items on the scale measure littering acts. It is a self-report questionnaire with response pattern in Likert format ranging from "Never=1 to Always =4". High score above the mean value indicates low frequency of REB and low score below the mean value indicates high frequency of REB. An alpha co-efficient of .94 and Equal length Spearman-Brown split half reliability of .83 were obtained for the scale in this study.

\section{Results and Discussion}

According to Baron and Kenny (1986), for researchers to claim a mediating relationship, three conditions must be met. First, there must be a significant relationship between the independent variable and the mediator. If the mediator is not associated with the independent variable, then it cannot mediate anything. Second, there must be a significant relationship between the mediator and the dependent variable. Third, there must be a significant relationship between the independent variable and the dependent variable. The final step involves demonstrating that when the mediator (environmental attitude) and the independent variables (selfconcept and environmental self-efficacy) are regressed simultaneously on the dependent variable (responsible environmental behaviour), the previously significant path between the independent variable and the dependent variable is reduced greatly, if it does not become non-significant. In the present study, prior to testing the mediatory hypothesis, estimation of the relationship among variables of study was established to assess whether sufficient correlation exists among the variables to proceed with the analysis. The results in Table 1 provide preliminary support for the significant relationships among the variables of the study. Thus a mediation analysis is appropriate.

As shown in Table 1, the results indicate significant positive relationships between self-concept $\quad(\mathrm{r}=.70 ; \quad \mathrm{p}<.01)$, environmental self-efficacy $(r=.34 ; \mathrm{p}<.01)$, and environmental attitude. Thus, it appears that when self image becomes more positive, and when people's judgments of their capabilities to organize and execute environmental related action increase, environmental attitude is likely to become more favourable, confirming hypothesis one. These findings are generally similar to findings elsewhere (see Adams, 2003; Corbett, 2005; Hines et al. 1987; Hwang et al. 2000). Results also indicate significant negative relationships between environmental attitude $(\mathrm{r}=-.24 ; \mathrm{p}<.01)$, self-concept $(\mathrm{r}=-.16$; $\mathrm{p}<.01)$, environmental self-efficacy $(\mathrm{r}=-.13$; $\mathrm{p}<.01)$ and responsible environmental behaviour, indicating when residents have low self-concept, and low perception of ability to organize and execute environmental related action, they are likely to perceive themselves as having low tendency to exhibit responsible environmental behaviour. These findings confirm hypothesis 2. Similar findings have been reported (see Adams, 2003; Busch, Fallan, \& Petterson, 1996; Corbett, 2005; Hines et al. 1987; Hwang et al. 2000; Mischel, 1986).

The summary of beta coefficients of the variables entered into simple linear multiple regression analysis reveals significant contributions of self-concept, environmental self-efficacy to environmental attitude, and responsible environmental behaviour respectively as presented in Table 2 . In model 1 , the results reveal that self-concept $(\beta \square=$ 0.66., $\mathrm{t}=35.83 ., \mathrm{p}<.01)$ and environmental self efficacy $(\beta \square \square=.32 ., \mathrm{t}=03.64 ., \mathrm{p}<.01)$ respectively contributed significantly to environmental attitude. This finding suggests that residents with high self-concept perceive themselves as exhibiting more favourable environmental attitude than residents with low self-concept. Residents with high environmental self efficacy also perceive themselves exhibiting more favourable environmental attitude than residents with low 
environmental self-efficacy. An explanation for this finding is that individual attempt to enhance many aspects of self including selfconcept and environmental self-efficacy through their disposition towards the environment. So residents with high selfconcept and environmental self-efficacy are likely to exhibit more favourable environmental attitude. In Ibadan, it is possible that positive self image and "I can do belief" of individuals who score high on self-concept and environmental self-efficacy inhibit them from imitating negative environmental attitude of the majority of the residents of Ibadan, hence, their more favourable environmental attitude. That self-concept and environmental selfefficacy predict environmental attitude is consistent with finding of Hines et al (1987) who reported similar result.

In model 2 , self-concept $(\beta \square=-0.16$, $\mathrm{t}=-4.82 ., \mathrm{p}<.05)$, and environmental self efficacy $(\beta \square \square=-0.11 ., \mathrm{t}=3.08 ., \mathrm{p}<.05)$ contribute significantly to responsible environmental behaviour. These findings are consistent with previous literature in this area (e.g. Adams, 2003; Busch, Fallan \& Pettersen, 1996; Corbett, 2005; Hines et al, 1987, Hwang et al, 2000; Mischel, 1986) who reported similar findings. These findings may be due to the fact that people with high self-concept and high environmental self-efficacy are characterized with positive self-ratings, and view their personal lives and environment positively unlike those with low self-concept, and low environmental self-efficacy who may have low self-image, possibly due to lack of resources, or life frustration. Hence, selfperception of individuals with high self-

Figure 1: Path Model of Responsible Environmental Behaviour concept and high environmental self-efficacy could motivate them to belief that environmental cleanliness is their personal responsibility. Jointly, self-concept, and environmental self efficacy contribute significantly to responsible environmental behaviour $\mathrm{R}^{2}=.06$; $(\mathrm{F}(2,1357)=653.398$; $\mathrm{p}<.001)$. These results offer initial support that a combination of self-concept and environmental self-efficacy may enhances responsible environmental behaviour.

Model 3 is a test of mediation. Results show that environmental attitude $(\beta \square \square=$ 0.23., $\mathrm{t}=-8.53 ., \mathrm{p}<.01)$ significantly mediates the relationships between self-concept, environmental self-efficacy, and responsible environmental behaviour. Inclusion of environmental attitude in Model 3 increases the significant contributions of self-concept, and environmental self-efficacy to responsible environmental behaviour, suggesting that environmental attitude significantly moderates the relationship between self-concept, environmental self-efficacy, and responsible environmental behaviour. Results of this analysis, as presented in Table 2, provide support for hypothesis 3. This finding makes sense when considered in light of previous research. Research evidence (e.g., Johnson et al., 2004; Monroe et al., 2000; McKenzieMohr \& Smith, 1999) suggests that information about people's attitude mediates the relationship between personal characteristics and behaviour. The paths linking the independent variables to mediating variable and to the dependent variable are presented in Figure 1.

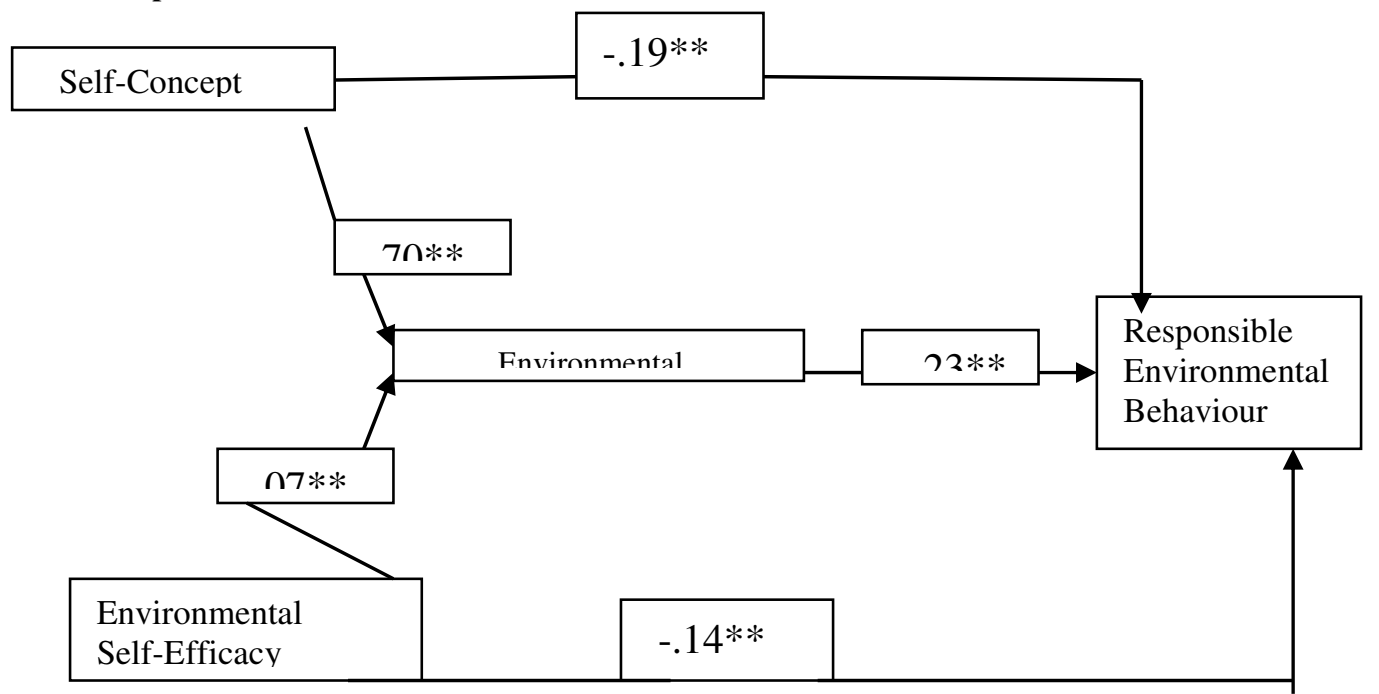




\section{Conclusion}

The results of the present study demonstrated that self-concept and environmental self efficacy are significantly related to responsible environmental behaviour of respondents. The significant relationship between self-concept, environmental selfefficacy, environmental attitude, and responsible environmental behaviour indicate that low levels of self-concept and environmental self-efficacy may inhibit favourable environmental attitude, and tendency to engage in responsible environmental behaviour. This implies that without significant improvement in individuals' self-image and environmental self-efficacious, environmental attitude and responsible environmental behaviour may not improve. Interestingly, environmental attitude is a crucial link in these relationships. This suggests the need to consult experts with skills and knowledge about human attitudes (e.g. environmental psychologists, social and personality psychologists, and other in related disciplines) to design attitude change strategies that would incorporate self-concept and environmental self-efficacy in order to enhance more responsible environmental behaviour among residents of high density areas in Ibadan metropolis.

In conclusion, findings from this study have shown that jointly and independently, selfconcept and environmental self-efficacy could

\section{References}

Adams, W. J. (2003), Promoting environmentally responsible behaviour: An evaluation of the global learning and observations to benefit the environment (Globe Programme. An Unpublished Master's Thesis. South Africa: University of South Africa.

Ajzen, I. (1987), Attitudes, traits, and actions: dispositional prediction of behaviour in personality and social psychology. In L. Berkowitz (ed.), Advances in Experimental Psychology, New York: Academic Press. pp. 1-63.

Arnould, E, Price, L. and Zinkhan, G. (2004), Consumers $\left(2^{\text {nd }} E d\right.$.). New York: Irwin, McGraw Hill.

Axerold, L. J, and Lehman, D. R. (1993), Responding to environmental concerns: What Factors guide individual action? Journal of Environmental Psychology, 13, 149-159.

Baron, R.M, and Kenny, D. A. (1986) The moderator-mediator variable distinction in be relied upon by policy formulators in order to foster more favourable environmental attitude, and to enhance more responsible environmental behaviour respectively. Additionally, environmental attitude strengthens the relationship between individuals' inherent dispositions and their environmental behaviour. It is therefore suggested that the government at the Federal, State and Local government levels, policy formulators, various stakeholders in the agenda to keep Ibadan city clean, and by extension the whole of Oyo State should embrace research findings, provide fund for seminar, training of trainers, and dissemination of research findings. They should also provide necessary facilities, and take actions to improve environmental attitude and responsible environmental behaviour among residents of Ibadan metropolis. The current study is not without limitation, this limitation is, however, common to survey data. Given that all the variables in this study were measured using self-report scales, there is a risk common method variance could have biased findings. This limitation notwithstanding, this study has contributed significantly to environmental psychology literature by demonstrating the relevance of environmental attitude in personenvironment transactions among residents of high density areas in Ibadan metropolis, Nigeria.

social psychological research: conceptual, strategic, and statistical considerations. Journal of Personality and Social Psychology, 51(6), 1173-1182.

Busch, T, Fallan, L. and Petterson, A. (1998), Disciplinary differences in job satisfaction, self-efficacy, goal commitment and organizational commitment among faculty employees in Norwegian colleges: an empirical assessment of indicators of performance. Quality in Higher Education, 4(2), 137-157.

Corbett, J. B. (2005), Altruism, self-interest, and the reasonable person model of environmentally responsible behaviour. Science Communication, 26(4), 368-389.

Devins, G. M, Beanlands, H., Mandin, H. and Paul, L.C. (1997), Psychosocial impact of illness intrusiveness moderated by self concept and age in end-stage renal disease, Health Psychology, 16, (6), 529-538. 
Eagly, A. H. and Chaiken, S. (1993), The psychology of attitudes. Fort Worth: Harcourt Brace Jovanovich.

Federal Military Government Decree No 58 of $30^{\text {th }}$ December 1988.

Hamachek, D. E. (1981), Encucentros con el yo (Encounters with the ego). Mexico: Interamericana.

Hansman, R, and Scholz, R.W. (2003), A two step informational strategy for reducing littering behaviour in a cinema. Environment and Behaviour, 35(6), 752-762.

Harkness, J, Scholz, E. and Stadler, S. (2002), ISSP Germany 2000 environment II: ZUMA report on the Germany study. London: National Center for Social Research.

Hines, J. M, Hungerford, H.R. and Tomera, A. N. (1987), Analysis and synthesis of research on environmental behaviour. A meta-analysis. Journal of Environment Education, 18, 1-8.

Holahan, C. J. (1982), Environmental psychology. New York: Random House.

Hwang, Y.-H, Kim, S.-I. and Jeng, J.-M. (2000), Examining the causal relationships among selected antecedents of responsible environmental behaviour. The Journal of Environmental Education, 31, 19-25.

Iwata, O. (2001), Attitudinal determinants of environmentally responsible behaviour, Social Behaviour and Personality, 25, 233-240.

Johnson, C. Y, Bowker, J. M. and Cordell, H. K. (2004), Ethic variation in environmental belief and behaviour: an examination of the new ecological paradigm in a social psychological context. Environment and Behaviour 36(2), 157-86.

Lawshe, C. H. (1975), A Quantitative approach to content validity. Personnel Psychology, 32, 91-108.

Mabogunje, A. I. (1962). The growth of residential districts in Ibadan. Geographical Review, 56-77.
McKenzie-Mohr, D. and Smith, W. (1999), Fostering sustainable behaviour: An introduction to community based social Marketing. Gabriola Island, BC: New Society Publishers.

Mischel, W. (1986), Personality and Assessment. New York: Wiley.

Monroe, M. C, Day, B. A. and Greiser, M. (2000), GreenCom weaves four strands. In B.A. Day and M. Monroe (eds.), environmental education and communication for a sustainable world, 3-6, Washington DC: Academy of Educational Development.

Ojedokun, A. O. (2009), Influence of psychosocial factors and mediatory role of environmental attitude on responsible environmental behaviour among residents of high density areas in Ibadan metropolis. Unpublished doctoral dissertation. University of Ibadan, Ibadan, Nigeria.

Osgood, C. E, Suci, G. J. and Tannenbaum, P. H. (1957), The measurement of meaning. Urbana, IL: University of Illinois Press.

Oyo State Government Edict. (1997), Gazette, 22 (8). Ibadan: Ministry of information, community development, sport and culture, Ibadan.

Schultz, P. W, Shriver, C., Tabanico, J. J., \& Khazian, A. M. (2004). Implicit connections with nature. Journal of Environmental Psychology, 24, 31-42.

Shavelson, R. J, Hubner, J. J. and Stanton, G. C. (1976), Self-concept: Validation of construct interpretations. Review of Educational Research, 46, 407-441.

Sivek, D. J, \& Hungerford, H. R. (1989-1990). Predictors of responsible environmental behaviour in members of three Wisconsin conservation organizations. Journal of Environmental Education, 21(2), 35-40. 
Table 1: Linear Correlation Matrix Showing Relationships among Variables of the Study ( $\mathrm{n}=1360)$

\begin{tabular}{|l|ccrr|}
\hline Variables & 1 & 2 & 3 & 4 \\
\hline 1. Responsible Environmental Behaviour & $-\overline{4}^{* *}$ & & & \\
2. Environmental Attitude & $-.16^{* *}$ & $-.70^{* *}$ & & \\
3. Self-Concept & $-.13^{* *}$ & $.34^{* *}$ & - & \\
4. Environmental Self Efficacy & 152.97 & 79.29 & 43.56 & 14.96 \\
$\quad$ Mean & 32.18 & 13.53 & 9.17 & 2.90 \\
S.D &
\end{tabular}

"Correlation is significant at the 0.05 level (2-tailed), ${ }^{* *}$ Correlation is significant at the 0.01 level (2tailed)

Table 2: Multiple Regression Analysis of Self-Concept, Environmental Self-Efficacy and Environmental Attitude on Responsible Environmental Behaviour

\begin{tabular}{|c|c|c|c|c|c|}
\hline Paths & & $\beta$ & $\mathrm{t}$ & $\mathrm{R}^{2}$ & $\mathrm{~F}$ \\
\hline Model 1 & & & & & $653.938 * *$ \\
\hline Self-Concept & EA & .66 & $35.83^{* *}$ & 0.49 & \\
\hline Environmental Self Efficacy & EA & .32 & $03.64 * *$ & & \\
\hline Model 2 & & & & & \\
\hline Self-Concept & REB & -.16 & $-4.82 *$ & 0.06 & $39.52 * *$ \\
\hline Environmental Self Efficacy & REB & -.11 & $-3.08 *$ & & \\
\hline Model 3 & & & & & \\
\hline Self-Concept & REB & -.19 & $-5.38 *$ & & \\
\hline Environmental Self Efficacy & REB & -.14 & $-3.80^{*}$ & 0.18 & $32.09 * *$ \\
\hline Environmental Attitude & REB & -.23 & $-8.53^{* *}$ & & \\
\hline
\end{tabular}

Note: $* * \mathrm{p}<.001$

Key: EA= Environmental Attitude, REB= Responsible Environmental Behaviour 